\title{
SUMBER DAYA GENETIK DAN PENGETAHUAN TRADISIONAL TERKAIT SUMBER DAYA GENETIK UNTUK KEMAKMURAN*
}

\author{
Aktris Nuryanti \\ Fakultas Hukum Universitas Tanjungpura \\ J1 Prof.H Hadari Nawawi, Pontianak \\ email : aktrisn@yahoo.com
}

\begin{abstract}
Indonesia as a mega biodiversity country is very attractive for bioprospectors. The complementarity between SDG and PT-SDG in the SDG preservation considered those must be managed by the same institutions that their function as development resource could be fullest utilized. And look at the complexity of managing the SDG and PT-SDG it is recommended that National Competent Authority agencies is to be set up under the president or vice president responsibility.
\end{abstract}

Keywords: SDG and PT-SDG, resource development, the National Competent Authority

\section{Abstrak}

Indonesia adalah mega biodiversity country yang sangat menarik bagi para bioprospektor. Saling kelindan SDG dan PT-SDG dalam pelestarian SDG menyebabkan SDG dan PT-SDG harus dikelola oleh lembaga yang sama agar fungsinya sebagai sumber daya pembangunan dapat didayagunakan secara maksimal. Dan melihat pada kompleksitas pengelolaan SDG dan PT-SDG maka disarankan agar lembaga National Competent Authority yang akan dibentuk itu berada dalam tanggungjawab presiden/wakil presiden.

Kata kunci: SDG dan PT-SDG, Sumber Daya Pembangunan, National Competent Authority

\section{A. Pendahuluan}

\section{Latar Belakang}

Indonesia adalah mega biodiversity country, maka diasumsikan bahwa sumber daya genetik (SDG) yang terkandung didalamnya memiliki variasi yang cukup tinggi. Potensi ini telah menjadikan Indonesia sebagai salah satu negara tujuan bioprospeksi. Bioprospeksi biasanya melibatkan informasi yang terkandung dalam pengetahuan tradisional terkait sumber daya genetik (PTSDG).

Terdapat saling kelindan antara SDG dengan PT-SDG. PT-SDG telah berperan dalam pengembangan SDG untuk memenuhi kebutuhan hidup manusia kini dan akan datang. Nilai intrinsik PT-SDG serta nilainilai ekologis, genetik, sosial, ekonomi, ilmu pengetahuan, pendidikan, budaya, rekreasi dan estetika SDG merupakan dasar penting untuk pembangunan berkelanjutan dan kesejahteraan manusia.

Kerugian global SDG dan degradasi ekosistem, akan berpengaruh pada ketahanan pangan dan gizi, penyediaan dan akses terhadap air dan kesehatan masyarakat miskin pedesaan, serta keseluruhan kesejahteraan orang di seluruh dunia, termasuk generasi sekarang dan masa depan. PT-SDG, inovasi dan praktek masyarakat adat dan lokal memberikan kontribusi penting untuk konservasi dan pemanfaatan berkelanjutan SDG dan aplikasi yang lebih luas dapat mendukung kesejahteraan sosial dan penghidupan yang berkelanjutan.

Politik hukum nasional menjadikan SDG dan PT-SDG sebagai salah satu sumber daya pembangunan untuk mewujudkan kemakmuran rakyat. Dengan demikian maka semua usaha pengelolaan dan pemanfaatan

* Sebagian besar tulisan ini disarikan dari Penelitian Mandiri dengan judul “Pengetahuan Tradisional Petani”, DIPA Fakultas Hukum UNTAN 2014.

1. Kementerian Negara Lingkungan Hidup, 2008, Pengungkapan Asal-Usul (Disclosure of Origin) Sumber Daya Genetik Dan/Atau

Pengetahuan Tradisional Dalam Suatu Invensi Yang Diajukan Untuk Memperoleh Hak Paten, hlm.i.

2.UU No 11 Tahun 2013 tentang Pengesahan Protokol Nagoya, Konsideran. 
SDG dan PT-SDG harus bermuara pada kemakmuran rakyat.

Agar dapat berdayaguna sebagai sumber kemakmuran, SDG dan PT-SDG harus dikelola dengan baik. Politik hukum instrumental, UU No. 11 Tahun 2013 telah mengamanahkan dibentuknya National Competent Authority (NCA). Mengingat pengelolaan SDG yang tersebar dalam berbagai kementerian (kelautan, perikanan, peternakan, pertanian, kehutanan, lingkungan hidup dll), bioprospeksi yang berlanjut pada monopoli dan komersialisasi hak paten, serta kompleknya pengelolaan SDG dan PT-SDG, posisi NCA menjadi sangat strategis dan amanah tersebut menimbulkan tanya, di bawah koordinasi siapakah idealnya lembaga NCA tersebut?.

\section{Metode Penelitian}

Penelitian ini adalah penelitian doktrinal. Datanya berjenis sekunder yang diperoleh dari bahan-bahan hukum terutama laporan-laporan penelitian. Analisis dilakukan secara kualitatif dengan metode deduktif.

\section{Kerangka Teori.}

a. Pembentukan PT-SDG

Secara filasafati, pengetahuan adalah keseluruhan pemikiran gagasan, ide, konsep, dan pemahaman manusia tentang dunia dan segala isinya, termasuk manusia dan kehidupannya. Pengetahuan bersifat spontan dan belum dibakukan secara sistematis dan metodis. Gejala terbentuknya PT-SDG adalah karena ada sipengenal (subyek), dan SDG (obyek). Keduanya merupakan suatu kesatuan asasi bagi terwujudnya pengetahuan manusia terkait SDG. PT-SDG telah dikenal dan dipraktekkan dalam masa yang sangat panjang dari generasi ke generasi. Intergovernmental Committee (IGC) on Intellectual Property and Genetic Resources, Traditional Knowledge and Folklore (IP\&GRTKF) merekomendasikan PT-SDG sebagai 'substantive knowledge of the properties and uses of genetic resources held by indigenous peoples or local communities and which directly leads to a claimed invention. ${ }^{4}$ PT-SDG meliputi inovasi-inovasi, praktek-praktek, keahlian dan know-how yang diturunkan dari generasi ke generasi dalam konteks tradisional atau adat. ${ }^{5}$

\section{b. Landasan Yuridis Pengelolaan dan Pemanfaatan \\ Secara yuridis, landasan pengelolaan} dan pemanfaatan SDG dan PT-SDG adalah UUD NRI Tahun 1945 Pasal 33 ayat (3) yang menentukan "Bumi, air dan kekayaan alam yang terkandung di dalamnya dikuasai oleh negara dan dipergunakan untuk sebesar-besar kemakmuran rakyat". Kemudian Pasal 18B ayat (2) UUD NRI 1945 bahwa "Negara mengakui dan menghormati kesatuankesatuan masyarakat hukum adat beserta hak-hak tradisionalnya sepanjang masih hidup dan sesuai dengan perkembangan masyarakat dan prinsip NKRI yang diatur dalam UU'. Konstitusi Indonesia yang tergolong dalam green constitution ${ }^{6}$ menyebutkan bahwa "Setiap orang berhak hidup sejahtera lahir dan bathin, bertempat tinggal, dan mendapatkan lingkungan hidup yang baik dan sehat serta berhak memperoleh pelayanan kesehatan". (Pasal 28H ayat (1)).

Secara hirarki landasan yuridis PTSDG berikutnya adalah TAP MPR N0. IX Tahun 2001 Tentang Pembaruan Agraria dan Pengelolaan Sumber Daya Alam Pasal 4 huruf (j) yang menyebutkan bahwa "Mengakui, menghormati, dan melindungi hak masyarakat hukum adat dan keragaman budaya bangsa atas sumber daya agraria/sumber daya alam.". Dan Pasal 7 jo. Pasal 5 (f, g) yang menegaskan fungsi negara sebagai pengelola sumber daya alam. Kemudian TAP MPR No. XV/MPR/1998 tentang Penyelenggaraan Otonomi Daerah; Pengaturan; Pembagian, dan Pemanfaatan Sumber Daya Nasional, Yang Berkeadilan; Serta Perimbangan Keuangan Pusat Dan Daerah Dalam Kerangka Negara Kesatuan Republik Indonesia. menentukan bahwa Pemda berwenang mengelola sumber daya

3. Sonny Keraf dan Mikhael Dua, 2001, Ilmu Pengetahuan : Sebuah Tinjauan Filosofis, Yogyakarta: Kanisius, hlm. 23.

4. Joint Recommendation On Genetic Resources And Associated Traditional Knowledge, IGC, Twenty-Fourth Session, Geneva, April 22 to $26,2013$.

5. WIPO Practical Guide, 2014, Intellectual Property and Folk, Arts and Cultural Festivals, WIPO. hlm 23.

6.Jimly Asshiddiqie, Green Constitution, Nuansa Hijau Undang-Undang Dasar Negara Republik Indonesia Tahun 1945, Jakarta, Rajawali Pres, 2009, 4 
nasional dan bertanggungjawab memelihara kelestarian lingkungan.

Selanjutnya politik hukum instrumental seperti UU Nomor 5 Tahun 1983 tentang Zona Ekonomi Eksklusif Indonesia (ZEEI), angka 6 Konsideran UU menegaskan bahwa sumber daya hayati dan non hayati di ZEEI adalah modal dan milik bersama bangsa Indonesia sesuai dengan wawasan nusantara. UU Nomor 6 Tahun 1996 Tentang Perairan Indonesia Pasal 4 menyatakan "Kedaulatan Negara Republik Indonesia di perairan Indonesia meliputi laut teritorial, perairan kepulauan, dan perairan pedalaman serta ruang udara di atas laut teritorial, perairan kepulauan, dan perairan pedalaman serta dasar laut dan tanah dibawahnya termasuk sumber kekayaan alam yang terkandung di dalamnya". Di sektor kehutanan, UU Nomor 41 Tahun 1999 tentang Kehutanan Pasal 4 ayat (1) mengatur "Semua hutan di dalam wilayah Republik Indonesia termasuk kekayaan alam yang terkandung di dalamnya dikuasai oleh negara untuk sebesar-besar kemakmuran rakyat".

Convention on Biological Diversity (CBD) mendukung penerapan kedaulatan negara (sovereign right) atas SDG yang berada di wilayah jurisdiksinya seperti tercantum dalam Pasal 3 yaitu "States have, ....., the sovereign right to exploit their own resources pursuant to their own environmental policies....". Penjabaran sovereign right yang dianut CBD diserahkan pada sistem hukum negara masing-masing, asalkan tidak menimbulkan kerusakan lingkungan negara lain atau di luar wilayah jurisdiksinya. CBD menyebutkan bahwa negara anggota harus, sejauh mungkin dan sesuai dengan undang-undang nasional, menghormati, melestarikan dan menjaga pengetahuan, inovasi dan praktek masyarakat adat dan lokal yang mewujudkan gaya hidup tradisional yang relevan untuk konservasi dan pemanfaatan berkelanjutan keanekaragaman hayati dan memajukan penerapannya secara lebih luas dengan persetujuan dan keterlibatan pemilik pengetahuan, inovasi dan praktek dan mendorong pembagian yang adil dari keuntungan yang dihasilkan dari pemanfaatan inovasi dan praktek-praktek pengetahuan tersebut (Pasal 8(j)).

Berdasarkan paparan di atas, politik hukum Indonesia secara konsisten menetapkan bahwa SDG dan PT-SDG dikuasai oleh Negara dimana pengaturan dan pengelolaannya diarahkan untuk sebesarbesarnya kemakmuran rakyat. Berpijak pada konsep negara kesejahteraan sebagaimana yang dituangkan dalam UUD 1945, maka peran negara untuk mengusahakan kesejahteraan bagi rakyatnya menjadi keharusan. Konsekuensinya, berbagai aktifitas kebijakan harus mengkaitkannya dengan pencapaian kemakmuran atau kesejahteraan rakyat. ${ }^{7}$

Politik hukum dasar Pasal 33 UUD NRI 1945 menunjukkan, bagaimana pikiran dan ide para pendiri negara melindungi bangsa dan tanah air Indonesia dalam bingkai kesatuan, dan kehati-hatian dalam pemanfaatan kekayaan bangsa yang merupakan Rahmat Allah Tuhan Yang Maha Kuasa. Pengelolaan kekayaan bangsa tersebut harus dilandasi oleh nilai-nilai keadilan sosial.

Penafsiran penguasaan negara harus dikaitkan dengan kedudukan negara sebagai entity yang berdaulat. Oleh karenanya, kewenangannya meliputi pengaturan hal-hal yang berada di wilayah kedaulatannya, meskipun diluar kepemilikannya, termasuk di dalamnya untuk menarik pemilikan orang lain untuk dikuasai negara. ${ }^{8}$ Penguasaan negara mengandung arti bahwa baik SDG maupun PT-SDG adalah milik publik oleh kolektivitas rakyat. ${ }^{9}$

Sebagai pemilik rakyat memberikan mandat kepada negara untuk mengadakan kebijakan (beleid), tindakan pengurusan (bestuursdaad), pengaturan (regelendaad), dan pengelolaan (bestuursdaad). Untuk itu negara (dalam hal ini Pemerintah) dapat mengeluarkan dan mencabut fasilitas, ijin, linsensi dan konsesi untuk mendayagunakan SDG yang dikelolanya.

7. Muhammad Arifin, ”Penanganan Kemiskinan Dalam Upaya Mewujudkan Negara Kesejahteraan”, Jurnal Ilmu-Ilmu Sosial, Vol 9, No 3 Oktober 2008 , hlm. 347

8. Maruarar Siahaan, 2008 Undang-Undang Dasar 1945: Konstitusi yang Hidup, Jakarta, Sekretariat Jenderal dan Kepaniteraan Mahkamah Konstitusi, hlm 540-541; Harjono, 2008, Konstitusi Sebagai Rumah Bangsa, Jakarta, Sekretariat Jenderal dan Kepaniteraan Mahkamah Konstitusi, 157

9. Maruarar Siahaan,ibid. 


\section{B. Hasil dan Pembahasan \\ 1. Ragam PT-SDG}

PT-SDG tersedia lebih banyak dari pada ilmu pengetahuan mengenai SDG, karena PTSDG mencakup segala sesuatu yang diketahui manusia tentang SDG tanpa perlu telah dibakukan secara sistematis. PT-SDG dihasilkan oleh kegeniusan lokal dalam mengidentifikasi potensi-potensi SDG yang ada di suatu wilayah. PT-SDG masyarakat umumnya berkaitan dengan fungsi-fungsi SDG guna mendukung kehidupan manusia.

Secara garis besar masyarakat pemilik PT-SDG yang umumnya masih menerapkan gaya hidup tradisional menggunakan SDG untuk memenuhi kebutuhan hidupnya dan keberlanjutan komunitasnya, meliputi hal-hal yang bersifat material maupun spiritual, alam nyata dan alam ghaib. Berikut ini adalah PTSDG masyarakat tradisional khususnya di Kalimantan Barat, yang dikelompokkan berdasarkan fungsi-fungsinya dalam kehidupan masyarakatnya: ${ }^{10}$

a. Bahan pangan (makanan dan minuman).

Masyarakat mengenali Begonia spp. (riang) sebagai bahan campuran untuk memasak ikan yang memberikan rasa asam masakan. Daun riang juga bisa dimakan mentah untuk menghilangkan rasa haus selama perjalanan. Sapindaceae (rambutan) marga: Dimocarpus longan (kelengkeng), Lepisanthes amoena (Enggamak), Nephelium spp. (rambutan, 4 jenis), dan Pometia pinnata (kasai). Rambutan merupakan buah lokal yang biasa dibudidayakan di pekarangan rumah ataupun ditanam di "tembawang" yaitu Pola kebun buah lokal campuran yang ditanam pada lokasi bekas ladang ( hutan muda') dan kemudian dibiarkan tumbuh secara alami. Suku Euphorbiaceae seperti Baccaurea, Elateriospermum tapos (kelampai) dan 'Lemadau' (nama lokal), Baccaurea angulata (ucong merupakan jenis yang favorit untuk dibudidayakan). Buahnya sangat atraktif, seperti belimbing berwarna merah darah dan rasanya manis kalau matang. Daun muda dan buah kelampai untuk dimakan, dan kayunya untuk bahan bakar dalam kondisi $1 \mathrm{e} m \mathrm{bab} / \mathrm{b}$ as ah sekalipun. Suku Arecaceae/Palmae merupakan suku yang menempati posisi sangat penting dalam hidup keseharian masyarakat Dayak. Palempaleman ini memiliki manfaat ganda, selain untuk bahan makanan juga berguna untuk bahan anyaman, tali temali, dan bahan/material kerajinan tangan. Suku ini misalnya Calamus scipionum (rotan tunggal/we semamuk), Licuala pygmaea (gerenih), Pinangasp. (pinang moreng besar), Plectocomiopsis geminiflora (lalis), dan Salacca affinis var. borneensis (ridan). Umumnya yang dimanfaatkan adalah umbutnya, khusus untuk ridan (salak hutan) buahnya. Pada Moraceae, yang dimanfaatkan buah dan serat kulit kayu Artocarpus spp. (entawak, tekalong, pingan, pala munsoh, pedalai/terap) untuk dijadikan sebagai rompi/pakaian. Kelompok Bombacaceae (Durio spp. / durian). Kelompok Guttiferae atau manggis, buah matang berwarna kemerah-merahan dan isinya putih mulus, rasanya manis-asam. Buah yang dikeringkan juga sering dijual di pasar sebagai bumbu masak campuran ikan untuk memberikan rasa asam. Dedaunan seperti daun sengkubak, daun kunyit dan daun kassum lazim dipergunakan sebagai bahan penyedap rasa pada masakan. Suku Fagaceae jenis Lithocarpus spp. (empilik) dan Castanopsis (berangan) rasanya gurih dan berlemak seperti kacang jika direbus, bisa menggantikan kebutuhan akan karbohidrat dan lemak. Kelompok Zingiberaceae merupakan jenis yang banyak dibudidayakan untuk kebutuhan bumbu masak. Salah satu jenis yang tumbuh liar di hutan dan sering dikumpul untuk dijual di pasar adalah Etlingera elaterior (kecalak). Bagian yang dimanfaatkan adalah kuncup bunganya untuk campuran sambal, baunya yang khas

10. Nico Andasputra dan Laurensius Tatang dkk (eds), 2010, Kalimantan Bumi yang Kaya Makanan, Pontianak: Institute Dayakologi..; Tjiu A, 2008, Tjiu, A, 2008, Identifikasi Flora Bernilai Penting Untuk Pengembangan Program Ecotourism di Wilayah DAS Embaloh, Taman Nasional Betung Kerihun, Kabupaten Kapuas Hulu - Kalimantan Barat, WWF-Indonesia dan Balai Besar Taman Nasional Betung Kerihun (TNBK) laporan survey, tidak dipublikasikan.; Daliman, Thomas, 1995, Kelembagaan Dayak Kanayatn di Kabupaten Pontianak, LBBT-Pontianak, Laporan Penelitian, tidak dipublikasikan.; Marfuah Wardani, 2008, "Keragaman Potensi Tumbuhan Berguna di Cagar Alam Mandor Kalimantan Barat", Jurnal Penelitian Hukum dan Konservasi Alam, Vol. V No. 3 hlm 251-266.; Fitri Damayanti at.all, 2011, “Diversity of Nephentes spp. In West Kalimantan”, International Journal of Biodiversity and Conservation, Vol. 3 (13) hlm 705-706. 
memberikan rasa khusus. Jenis-jenis lain untuk bahan pangan adalah Kembayau (Canarium spp.), Mawang (Mangifera pajang), dan Petai (Parkia speciosa), petai hutan (Albizia lebbeck, dan cempedak utan (Artocarpus heterophyllus). Saprofit atau jamur merupakan jenis yang tidak kalah pentingnya sebagai sumber penyedia makanan di hutan. Berbagai jenis jamur yang enak dimakan seperti: jamur mata pelanduk (Calostoma sp.), Cookiena tricholoma (kulat mangkuk), dan kulat minyak (Pleurotus ostreatus). Masih banyak SDG bahan makanan misalnya ikan, unggas, mamalia dll. Beberapa produk SDG diantaranya bahkan telah dipasarkan di pasar modern seperti asam paya (Eliodoxa conferta) dan Lithocarpus sundaicus. Di China dan Malaysia, buah dari marga Lithocarpus dijual dalam bentuk permen coklat yang disebut Hazelnuts yang merupakan lisensi dari Swiss. Namun tidak dicantumkan nama species Lithocarpus yang dipergunakan. ${ }^{11}$

b. Tumbuhan sebagai bahan obat-obatan PT-SDG mengenai bahan obat antara lain dari: suku Leguminosae yang sebagian besar adalah akar/liana mengandung air yang bermanfaat untuk pengobatan seperti untuk obat batuk. Jenis akar kuning (Fibraureatinctoria) bermanfaat khusus untuk mengobati sakit kuning (liver). Bagian yang digunakan adalah batang dan juga akarnya. Pasak bumi (Eurycoma longifolia), penangkal malaria namun umumnya lebih diyakini memberikan efek keperkasaan bagi pria. Dari famili Sterculiaceae, Scaphium macropodum atau Empokong (istilah lokal di suku Dayak Iban), kembang semangkok (Melayu), buahnya untuk mengurangi penyakit panas dalam. Jenis ini mendapatkan namanya dari buahnya yang kalau direndam dalam air dingin di mangkok maka daging buahnya akan mengembang memenuhi ruang pada mangkok secara penuh. Jelatang (Dendrocnide stimulans) suatu tumbuhan dengan miang-miang halus pada daun bisa menimbulkan rasa gatal dan iritasi yang sangat menyakitkan. Namun rasa gatal ini bisa dihilangkan dengan memanfaatkan daun tumbuhan ini sendiri dengan cara dipanaskan dan ditempel pada bagian yang terkena miang jelatang. Kantung semar (Nephenthes ampullaria) oleh masyarakat tradisional dikenal sebagai obat sakit perut yaitu dengan cara merebus akar dan daunnya. Air yang terkandung dalam kantong yang masih tertutup sebagai tetes mata untuk menyembuhkan mata merah.

\section{c. PT-SDG bahan bangunan}

Hutan masih sering dipandang sebagai penghasil kayu, meskipun ada manfaat non kayu dan jasa lingkungan yang diciptakan iklim mikro hutan yang sangat berpengaruh bagi kehidupan umat manusia. Kayu untuk bahan bangunan umumnya dari suku Dipterocarpaceae (meranti-merantian) yang didominasi oleh marga Shorea spp. (meranti), selebihnya ada Dryobalanops spp. (kelansau dan keladan), dan Dipterocarpus spp. (ensurai) serta Hopea sp. (merawan). Dalam dunia perdagangan, dikenal kelompok nama meranti merah yang sangat diminati, meranti kuning, meranti putih, dan balau/selangan batu. Lainnya adalah Myrtaceae (ubah) dan Annonaceae (semukau), cenaga/bintangur (Calophyllum spp.) Masyarakat mengenal pula jenis kayu yang sekaligus juga berpotensi ramuan obat misalnya pulai (Alstonia pneumatophora) kayunya cocok untuk bahan kayu lapis, peti kemas, ukiran sedangkan getahnya digunakan untuk obat penyakit kulit karena kulit batangnya mengandung alkaloid. Selain itu ada pula nyatoh kali awar (Payema acuminata) yang memiliki kegunaan kayunya untuk konstruksi rumah yang tidak langsung berhubungan dengan tanah, perabot rumah tangga, pintu berukir, panel, kadang-kadang untuk perahu, buahnya dapat dimakan. Rumah betang, di Dusun Ulu' Palin Kabupaten Kapuas Hulu dengan panjang 286 meter, tiang bangunannya dari jenis Belian (Eusideroxylon zwageri) beratapkan sirap dan banyak yang masih diikat dengan rotan. ${ }^{12}$

d. PT-SDG pelengkap upacara adat dan kegiatan social Masyarakat tradisional dikenal memiliki

\footnotetext{
11. Marfu'ah Wardani, 2008, "Keragaman Potensi Tumbuhan Berguna di Cagar Alam Mandor Kalimantan Barat”, Jurnal Penelitian Hutan dan Konservasi Alam, Vol. V No.3:256.

12. http://www.gallery-kapuashulu.org/id/entry/sungaiulupalin-tour diakses tanggal 14 September 2014
} 
nilai-nilai tradisi dan sosial yang kuat. Nilainilai ini biasanya direalisasikan dalam berbagai bentuk upacara adat. Kelompok kayu Annonaceae (selukai) digunakan kulit kayunya untuk mengusir roh halus, khususnya di bilik dimana ada ibu-ibu yang lepas bersalin dan mempunyai bayi (di suku Dayak Iban dan Tamambalo).

\section{e. PT-SDG tanaman hias}

Kelompok tumbuhan yang bernilai estetika misalnya suku Begonia spp., Cyrtandra spp., Pinanga spp. (Pinang moreng), Anggrek (Orchidaceae) dan keladi (Araceae). Riang juga punya potensi sebagai tanaman hias karena struktur daunnya yang cantik dan juga bunganya indah. Kelompok Cyrtandra, berdaun dan berbunga indah dan sering merupakan tumbuhan bawah yang mudah untuk dibudidayakan. Pinang moreng selain dimanfaatkan buahnya untuk 'nyirih', penampilan fisiknya juga cantik.Anggrek yang terkenal adalah anggrek hitam (Coelogyne pandurata) kemudian ada anggrek tanah daun ungu (C.Speciosa) dan anggrek pohon (phalaenopsis violance). Kantong semar (Nephenthes), seperti dari suku Liliaceae maupun Rubiaceae dll.

\section{f. PT-SDG bahan kayu bakar}

Umumnya kayu bahan bakar berasal dari kelompok kayu suku Euphorbiaceae (rambai-rambaian). Kayu kelampai (Elateriospermum tapos), bernilai istimewa karena kayunya yang masih hidup bisa langsung terbakar dengan nyala api yang bagus, sehingga dapat menjadi andalan di musim penghujan.

\section{g. PT-SDG bahan kerajinan.}

Serat kayu yang lentur, dan tali menjadi bahan utama sejak dahulu kala sebelum ditemukannya bahan serat dan tali sintetis. Suku Arecaceael Palmae yang terdiri dari beragam rotan menjadi andalan utama, selain itu suku Annonaceae (semukau) dan Moraceae (entawak, tekalong, pingan, dan pedalai) yang terkenal berserat panjang dan sangat alot menempati posisi yang penting dalam dunia anyam-menganyam. Tikar rotan, perkakas dapur, pengamben/ladong umumnya memanfaatkan rotan sebagai bahan baku utama, untuk tali pengikatnya digunakan serat kayu semukau dan pedalai. Jenis rotan yang digunakan misalnya rotan sega (Calamus caesius), rotan tali (Calamus diepenhorstii), rotan cincin (Daemanorops didymophylla) (Daemanorops elongatus). Dahulu kala, tenun trasidional memanfaatkan serat seperti daun lembak (Curculigo orchioides) untuk dipintal menjadi benang untuk bahan kain tenun.

\section{h. PT-SDG pakan satwa liar}

Kelompok kayu Ara (Ficus spp.) merupakan jenis yang paling penting dalam menyediakan pakan buat berbagai macam satwa liar seperti burung dan primata. Jenis Berangan (Castanopsis spp.) dan empilik (Lithocarpus spp.) juga berperanan penting sebagai pakan terutama bagi kelompok primata. Pohon kempas (Koompassia malaccensis) dan tapang (Koompassia excelsa) sangat penting bagi keberlangsungan hidup lebah madu (Apis dorsata). Lebah madu menyukai jenis kayu ini sebab arsitektur pohonnya yang memang cocok untuk bersarang. Berkarakter tinggi, banyak percabangan dan menjuntai, kokoh, dan liat merupakan ciri-ciri pohon ini yang sangat disukai lebah madu. Teras dan gubal kayunya berpasir dan kasar sehingga tidak diminati sebagai kayu bahan bangunan. Jenis kayu ini telah ditetapkan dengan nilai adat suku Dayak sebagai kayu larangan adat. Jenis-jenis lain durian, kembayau, ubah, kemali (Leea sp.), juga merupakan pakan utama satwa liar.

\section{i. Tumbuhan untuk manfaat lain}

Kayu entangur/cenaga (Calophyllum spp.) dan perawan (Shorea leprosula) merupakan jenis kayu penting untuk membuat sampan. Pada umumnya papan lantai dan dinding sampan menggunakan kayu entangur/cenaga dan perawan. Sementara lunas dan tulang/kerangka perahu menggunakan jenis Meranti merah. Banir kayu kempas (Koompassia malaccensis) untuk mendulang emas karena kuat dan tahan air. Cinnamomum iners atau kayu lawang memiliki bau yang sangat harum, seperti wangi sarsaparilla. Kulit kayu ini dicampur dengan bahan-bahan lain berguna untuk makan sirih (nyirih).Untuk menuba ikan digunakan kulit kayu enselan (Burseraceae), ikan-ikan kecil yang terkena air rendaman kulit kayu ini akan 
mabuk dan mudah untuk dikumpulkan.

\section{Dinamika Pengakuan PT-SDG}

Dinamika pengakuan PT-SDG semakin kuat dan telah menjadi pembicaraan di tingkat internasional seperti UN-CBD, WIPO maupun WTO. PT-SDG diakui perannya tidak hanya telah bermain dalam keberlangsungan hidup masyarakat pemiliknya tetapi juga dalam keberlangsungan hidup umat manusia secara keseluruhan.

CBD Pasal 8(j) mengakui bahwa PTSDG telah memainkan peran penting dalam pelestarian SDG sehingga menyatakan perlu adanya pembagian yang adil dan seimbang dari keuntungan yang dihasilkan atas pemanfaatan pengetahuan ini. In line dengan CBD, Protokol nagoya (2010) menegaskan bahwa akses terhadap SDG dan PT-SDG harus tunduk pada prior informed consent (PIC) dari pihak penyedia SDG, dan PIC harus melibatkan pemilik PT-SDG.

Di tingkat Internasional, untuk merespon hilangnya SDG pangan dunia dibentuklah The Consultative Group on International Agricultural Research (CGIAR) pada tahun 1971. CGIAR bertujuan menumbuhkan pertanian berkelanjutan melalui pencapaian ilmiah berkualitas tinggi yang bermanfaat bagi masyarakat miskin melalui ketahanan pangan yang semakin kuat, nutrisi dan kesehatan yang lebih baik, penghasilan yang tinggi, dan manajemen SDA yang lebih meningkat. Tahun 1974, CGIAR mendirikan International Board for Plant Genetic Resources (IBPGR) dengan misi mengkoordinasikan program SDG tanaman internasional termasuk didalamnya misi koleksi sekaligus membangun dan mengembangkan bank gen nasional, regional dan internasional. Internasional (International Agricultural Research Centres-IARCs) adalah bank gen, dengan jumlah aksesi sekitar 666.000 , ${ }^{13}$ yang terdiri dari tanaman pangan, pakan ternak, dan pohon hutan pertanian. Tahun 1994, CGIAR setuju memasukkan koleksi yang diadministrasikannya dibawah administrasi FAO berbentuk trusteeship. ${ }^{14}$ Tahun 2006, IBPGR merger dengan ITPGRFA dalam suatu gerakan yang dinamakan Global System for Conservation and Utilization of PGR di bawah koordinasi FAO.

Keterlibatan Indonesia dalam kerangka FAO sejak tahun 1948, mau tidak mau melibatkan SDG pangan dan pertanian Indonesia dalam ajang tukar menukar benih/gen. Kepemilikan benih/gen Indonesia yang berada dalam koleksi ex situ kini perlu dipertanyakan, karena ada indikasi bahwa beberapa benih/gen dipertukarkan untuk kepentingan komersial dalam konteks HKI. Praktek ini dapat digolongkan ke dalam biopiracy. Apabila PT-SDG dilibatkan maka dapat pula terjadi misappropriation . Hawin pernah mengkonstatasi bahwa banyak PTSDG dicuri dan menjadi a starting point penelitian untuk mendapatkan hak paten. $\mathrm{D}$ a la m praktek biopiracy dan misappropriation pemilik SDG dan PT-SDG tidak menerima pembagian keuntungan dari pemanfaatannya.

Pengaturan SDG hasil pengembangan secara tradisional erat kaitannya dengan PTSDG Petani. Resolusi 5/89 FAO (29 November 1989) mengatakan: "Farmers' Rights mean rights arising from the past, present and future contributions of farmers in conserving, improving, and making available plant genetic resources, particularly those in the centres of origin/diversity. These rights are vested in the International Community, as trustee for present and future generations of farmers, for the purpose of ensuring full benefits to farmers, and supporting the continuation of their contributions, as well as the attainment of the overall purposes of the International Undertaking."

Lampiran Protokol Nagoya menyebutkan bahwa benefit sharing atau pembagian keuntungan dari pemanfaatan SDG dan PT-SDG bisa berupa keuntungan monoter dan non-moneter. Keuntungan moneter termasuk namun tidak terbatas pada

\footnotetext{
13. Bonwoo Koo, et.al, Conserving Genetic Resources For Agriculture: Counting The Cost, Brief, 2003. $\mathrm{http}: / /$ ageconsearch.umn.edu/bitstream/16485/1/rg030006.pdf dikunjungi terakhir tanggal 18 November 2014

14. David S. Tilford, 1998, "Saving The Blueprints: The International Legal Regime For Plant Resources", Case Western Reserve Journal of International Law, p. 424.

15. M. Hawin, 2009, Perlindungan Pengetahuan Tradisional di Indonesia, Pidato Pengukuhan Jabatan Guru Besar pada Fakultas Hukum Universitas Gadjah Mada, Yogyakarta.
} 
biaya akses, pembayaran di muka, pembayaran pada tahapan penting (milestone), dana amanah untuk konservasi, kepemilikan bersama atas HKI yang relevan dll. Sedangkan yang non-moneter misalnya berbagi hasil penelitian, partisipasi dalam pengembangan, pengakuan sosial, kepemilikan HKI, pelatihan, pengembangan kapasitas kelembagaan dll.

\section{Lembaga Pengelola SDG dan PT- SDG}

SDG dan PT-SDG Indonesia sangat berlimpah dan bernilai ekonomi, sehingga perlu dijaga kelestariannya dan dikembangkan agar dapat dimanfaatkan secara berkelanjutan sebagai sumber daya pembangunan untuk sebesar-besarnya kemakmuran rakyat. Politik hukum SDG dan PT-SDG sebagai sumber daya pembangunan membawa konsekwensi bahwa pengelolaan dan pemanfaatannya harus dilakukan sesuai dengan tujuan Negara, Politik hukum adalah kebijakan resmi tentang hukum yang akan diberlakukan dalam rangka mencapai tujuan negara. ${ }^{16}$ Nyoman mengatakan bahwa, politik hukum tidak berhenti dengan selesai dibuatnya undang-undang oleh lembaga pembuat undang-undang. Kadang-kadang dan bahkan kebanyakan undang-undang yang diciptakan masih memerlukan Kebijakan Pemerintah ataupun Keputusan Presiden, disamping lembaga-lembaga birokrasi yang diberi wewenang untuk melaksanakan kebijakan publik. $^{17}$

Salah satu materi pokok UU No. 11 Tahun 2013 tentang Pengesahan Protokol Nagoya adalah mengenai mekanisme kelembagaan National Competent Authority (NCA). National Focal Point (NFP) berfungsi menghubungkan Pemerintah Indonesia dengan Sekretariat UN-CBD. Sedangkan Politik hukum NCA National Competent Authority (N C A) mengamanahkan NCA sebagai institusi yang berwenang memberikan izin akses, penentuan kebijakan prosedur akses, dan persyaratan dalam persetujuan atas dasar informasi awal serta kesepakatan bersama dalam pemanfaatan SDG dan PT-SDG. Amanah ini menunjukkan bahwa NCA memiliki kewenangan yang luas dalam upayanya melestarikan, mengelola, dan mendayagunakan SDG dan PT-SDG sebagai sumber daya pembangunan untuk mewujudkan kemakmuran dan keadilan bagi rakyat Indonesia.

SDG dan PT-SDG saat ini dikelola secara tersebar oleh masyarakat pemilik PTSDG, berbagai lembaga penelitian dan pengembangan baik pada kementeriankementerian yang membidangi SDG seperti Lingkungan Hidup, Kesehatan, Pertanian, Perkebunan, Perikanan, Peternakan, Perairan, Kehutanan dll; Ristek-PT, LIPI, BPOM, LSM, lembaga-lembaga penerbitan. Oleh sebab itu maka pengelolaan SDG dan PTSDG oleh NCA agar dapat dimanfaatkan oleh bioprospektor atau yang lainnya bukanlah usaha yang ringan.

Dalam kaitan itu, kementerian yang membidangi SDG dapat menjadi penyumbang terbesar dalam identifikasi SDG dan PT-SDG, karena alat kementerian berada di tingkat pusat hingga ke daerah-daerah. Ditingkat lokal, hukum adat/lokal yang telah dipraktekkan dari generasi ke generasi dipandang ideal untuk dilembagakan kembali dengan tetap mempertahankan ciri tradisionalnya yang bersifat elastis, konkrit, religius dalam pengelolaan SDG dan PTSDG. Dengan demikian, NCA dapat memulai dari tingkat lokal karena PT-SDG bersifat lokal sesuai dengan keragaman SDG pada wilayah lokal tersebut dengan memberdayakan Pemda.

Hasil identifikasi SDG dan PT-SDG harus diketahui oleh masyarakat pengguna baik yang bersifat komersial maupun komersial. Artinya, NCA sekaligus merupakan bangunan sistem informasi SDG dan PT-SDG. Informasi PT-SDG akan sangat membantu bioprospektor dalam aktivitas bioprospeksi.

Keuntungan yang diperoleh dari pemanfaatan SDG dan PT-SDG, menjadi hak bioprospektor dan provider SDG dan PT-SDG dengan pembagian yang adil. Oleh karena itu agar provider mudah mengidentifikasi asal SDG dan PT-SDG maka data SDG dan PTSDG harus terdokumentasikan dengan baik dan tersusun dengan sistematis.

16. Mahfud, 2014, Politik Hukum di Indonesia, Jakarta, Rajawali Pers, hlm. 1.

17. Nyoman Serikat Putra Jaya, 2014, Politik Hukum, Semarang, Badan Penerbit Universitas Diponegoro, hlm.17. 
Melihat pada kompleksitas tugas dan wewenang NCA dalam pendayagunaan SDG dan PT-SDG sebagai sumber daya pembangunan tersebut di atas maka sebaiknya NCA bukan bagian dari organisasi kementerian melainkan menjadi tanggungjawab presiden/wakil presiden.

\section{Simpulan dan Saran}

Berdasarkan paparan di atas maka disimpulkan bahwa Indonesia adalah mega biodiversity country yang sangat menarik bagi para bioprospektor. Saling kelindan SDG dan PT-SDG dalam pelestarian SDG sebagai sumber pangan, papan, prasarana, pakan hewan dan ekspresi kultural serta kebutuhan lainnya, menyebabkan SDG dan PT-SDG harus dikelola oleh lembaga yang sama agar fungsinya sebagai sumber daya pembangunan dapat didayagunakan secara maksimal.

Dengan demikian disarankan agar NCA sebagai institusi yang berwenang memberikan izin akses, penentuan kebijakan prosedur akses, dan persyaratan dalam persetujuan atas dasar informasi awal serta kesepakatan bersama dalam pemanfaatan SDG dan PT-SDG harus segera dibentuk. Dan dengan melihat kompleksitas pengelolaan SDG dan PT-SDG disarankan pula agar NCA berada dalam tanggungjwab presiden/wakil presiden.

\section{DAFTAR PUSTAKA}

\section{Buku}

Andasputra, Nico dan Laurensius Tatang dkk (eds), 2010, Kalimantan Bumi yang Kaya Makanan, Pontianak: Institute Dayakologi.

Asshiddiqie, Jimly, 2009, Green Constitution, Nuansa Hijau Undang-Undang Dasar Negara Republik Indonesia Tahun 1945, Jakarta: Rajawali Press.

Daliman, Thomas, 1995, Kelembagaan Dayak Kanayatn di Kabupaten Pontianak, LBBT-Pontianak, Laporan Penelitian, tidak dipublikasikan

Djulaeka, 2014, Konsep Perlindungan Hak

Kekayaan Intelektual: Perspektif Kajian

Filosofis HaKI Kolektif-Komunal,

Malang-Jatim: Setara Press.

Harjono, 2008, Konstitusi Sebagai Rumah
Bangsa, Jakarta: Sekretariat Jenderal dan Kepaniteraan Mahkamah Konstitusi.

Hawin, M, 2009, Perlindungan Pengetahuan Tradisional di Indonesia, Pidato Pengukuhan Jabatan Guru Besar M. pada Fakultas Hukum Universitas Gadjah Mada.

Joint Recommendation On Genetic Resources And Associated Traditional Knowledge, IGC, Twenty-Fourth Session, Geneva, April 22 to 26, 2013.

Kementerian Negara Lingkungan Hidup, 2008, Pengungkapan Asal-Usul (Disclosure of Origin) Sumber Daya Genetik Dan/Atau Pengetahuan Tradisional Dalam Suatu Invensi Yang Diajukan Untuk Memperoleh Hak Paten.

Keraf, Sonny dan Mikhael Dua, 2001, Ilmu Pengetahuan: Sebuah Tinjauan Filosofis, Yogyakarta: Kanisius.

Mahfud MD, 2014, Politik Hukum di Indonesia, Jakarta: Rajawali Pers.

Serikat Putra Jaya, Nyoman, 2014, Politik Hukum, Semarang: Badan Penerbit Universitas Diponegoro.

Siahaan, Maruarar, 2008, Undang-Undang Dasar 1945: Konstitusi yang Hidup, Jakarta: Sekretariat Jenderal dan Kepaniteraan Mahkamah Konstitusi.

Tjiu A, 2008, Tjiu, A, 2008, Identifikasi Flora Bernilai Penting Untuk Pengembangan Program Ecotourism di Wilayah DAS Embaloh, Taman Nasional Betung Kerihun, Kabupaten Kapuas Hulu Kalimantan Barat, WWF-Indonesia dan Balai Besar Taman Nasional Betung Kerihun (TNBK) laporan survey, tidak dipublikasikan.;

WIPO Practical Guide, 2014, Intellectual Property and Folk, Arts and Cultural Festivals, WIPO.

\section{Perundang-undangan}

Undang-Undang Republik Indonesia Nomor 11 Tahun 2013 Tentang Pengesahan Protokol Nagoya Tentang Akses Pada Sumber Daya Genetik Dan Pembagian Keuntungan Yang Adil Dan Seimbang Yang Timbul Dari Pemanfaatannya Atas Konvensi Keanekaragaman Hayati).

Rancangan Undang Undang Pengetahuan Tradisional dan Ekspresi Budaya Tradisional. 


\section{Jurnal}

David S. Tilford, Saving The Blueprints: The International Legal Regime For Plant Resources, Case Western Reserve, Journal of International Law, Tahun 1998.

Fitri Damayanti dkk, Diversity of Nephentes spp. In West Kalimantan, International Journal of Biodiversity and Conservation, Vol. 3 (13) Tahun 2011.

Marfuah Wardani, Keragaman Potensi Tumbuhan Berguna di Cagar Alam Mandor Kalimantan Barat, Jurnal Penelitian Hukum dan Konservasi Alam, Vol. V No. 3 Tahun 2008.

Muhammad Arifin, Penanganan Kemiskinan Dalam Upaya Mewujudkan Negara Kesejahteraan, Jurnal Ilmu-Ilmu Sosial, Vol 9, No 3 Oktober 2008.

\section{Internet}

Bonwoo Koo, et.al, Conserving Genetic Resources For Agriculture: Counting The Co s t, $\quad$ B ri e f, 2003 . http://ageconsearch.umn.edu/bitstream/1648 5/1/rg030006.pdf dikunjungi terakhir tanggal 18 November 2014

h t t p : / / w w w . g a 11 e r y kapuashulu.org/id/entry/sungaiulupalin-tour, dkunjungi 12 Januari 2015 